\title{
Bandwidth Enhancement of Compact Monopole Antennas for Application in UWB Communication System
}

\author{
J. B. Jadhav. \\ Department of Electronics \& Tele Comm. \\ R. C Patel Institute of Technology, \\ Shirpur, India
}

\author{
P. J. Deore. \\ Department of Electronics \& Tele Comm. \\ R. C Patel Institute of Technology, \\ Shirpur, India
}

\begin{abstract}
In this paper a microstrip transmission line fed compact monopole antenna for the wide-band $(2.5 \mathrm{GHz}-11 \mathrm{GHz})$ communication system is designed and its performance is verified. In particular, we have simulated four types of wideband monopole antennas: rectangular, modified rectangular, circular and modified circular disk monopole antennas. Simple rectangular microstrip lines are used for feeding the monopole antennas. This compact monopole antenna designed works well for the whole UWB frequency band $3.1-10.6 \mathrm{GHz}$ from the IE3D simulation results. The compact antenna has the good performance including wideband impedance matching, reliable radiation pattern at all the frequencies. The novel antenna presented in this paper is expected to find application in future UWB system.
\end{abstract}

\section{Keywords}

Monopole antenna, microstrip-transmission line, Ultrawideband (UWB).

\section{INTRODUCTION}

Application of ultra-wideband (UWB) technology on wireless communication system has increased significantly in last eight years. Because the UWB technology has huge potential in the development of various present wireless communication systems, the U.S Federal Communication Commission (FCC) authorized the unlicensed use of the ultrawideband (3.1-10.6 $\mathrm{GHz}$ ) frequency spectrum for indoor and hand-held wireless communication since early February 2002. According to the released regulation, UWB technology received great attention in various fields for the short-distance $(<10 \mathrm{~m})$ wireless communications. Because of the ultra-wideband property, UWB technology has many benefits, which are high data rate (> $100 \mathrm{Mb} / \mathrm{s}$ ), low power consumption, compact, low cost, tremendous immunity to multipath interference and less hardware complexity. The UWB antennas anticipated in the open literature mainly focus on the slot and monopole antenna [2]-[5]. Wide slot antennas have an attractive property of providing a wide operating bandwidth. Broadband planar monopole antennas have received considerable attention owing to their attractive merits, such as ultrawide frequency band, good radiation properties, simple structure and ease of fabrication. The typical shapes of these antennas are rectangle [6], half-disc [7], circle, and ellipse [8].
GSM 1800, PCS 1900, IMT 2000, WLAN and UWB systems [10]-[12]. Many novel techniques were adopted in the past to achieve wide bandwidth of compact monopole antennas [6].Because of ease of the integration with integrated circuits, monopole antennas are fabricated on the printed circuit boards [13]. Parametric study of printed circular monopole antenna has been presented in [8], where the antenna performance is calculated by varying the size of substrate, feed length and ground plane. In this paper, the printed rectangular monopole antenna (RMSA) studied provides an impedance bandwidth from $2.5 \mathrm{GHz}$ to $11 \mathrm{GHz}$, which can be used for UWB communication systems. Various design parameters of the RMSA are varied such as dielectric constant of the substrate, feed gap, feed-line width, plate length, plate width, and substrate and ground plane width. During these parametric studies, the behavior of the $F_{L}$ of the bandwidth and $F_{H}$ of the bandwidth is studied.

Some UWB antennas are much more complex than other existing single band, dual band and multi-band antennas [8], [14], [15]. Most of the UWB monopole antennas investigated till today is non-planar as in [14]-[15] and due to their protruded structure, they can't be integrated with integrated circuits. Few researchers have also studied printed monopole antenna namely circular disk printed monopole antenna [8].

\section{GEOMETRY OF SOME COMPACT WIDEBAND MONOPOLE ANTENNAS AND SIMULATION RESULTS.}

\subsection{Rectangular wideband micro strip Monopole Antenna (RMSA)}

Antenna is the key element in the UWB systems. The motivation of UWB antenna design is to design a compact and simple antenna that introduces low distortions with large bandwidth. The geometry shown below is the compact rectangular monopole antenna (RMSA). The rectangular printed monopole antenna is printed on one side of the Glass epoxy (FR4) PCB substrate of thickness $1.59 \mathrm{~mm}$ and relative permittivity 4.4 and the partial ground plane is located on the other side of the substrate. The dimensions of the FR4 substrate are $\mathrm{w}=31.2 \mathrm{~mm}$ and $\mathrm{h}=44.2 \mathrm{~mm}$. The dimensions of the ground plane are $\mathrm{w}=31.2 \mathrm{~mm}$ and $\mathrm{hg}=18.2 \mathrm{~mm}$. The dimensions of the rectangular printed patch are $\mathrm{W}=11 \mathrm{~mm}$ and $\mathrm{L}=17 \mathrm{~mm}$. The antenna plate is fed by a microstrip line of 
characteristic impedance $50 \Omega$ having the stripwidth $\mathrm{w}_{\mathrm{f}}=2.6$ $\mathrm{mm}$. The printed plate is located at a feed gap $\mathrm{h}_{\mathrm{f}}=2 \mathrm{~mm}$ from the ground plane. The FR4 substrate is $\mathrm{H}=1.59 \mathrm{~mm}$ thick and the metal thickness is $35 \mu \mathrm{m}$. The RMSA was simulated using Method of Moments based IE3D simulation software. The geometric parameters of this structure can be adjusted to tune the return loss and bandwidth over range of frequency. Fig. 2 shows the simulated VSWR characteristics of the wideband monopole antenna from $2.5 \mathrm{GHz}$ to $11.5 \mathrm{GHz}$. Fig. 3 shows the simulated return loss vs frequency of the wideband monopole antenna. The frequency band for this antenna extends from $2.5 \mathrm{GHz}-11.5 \mathrm{GHz}$.

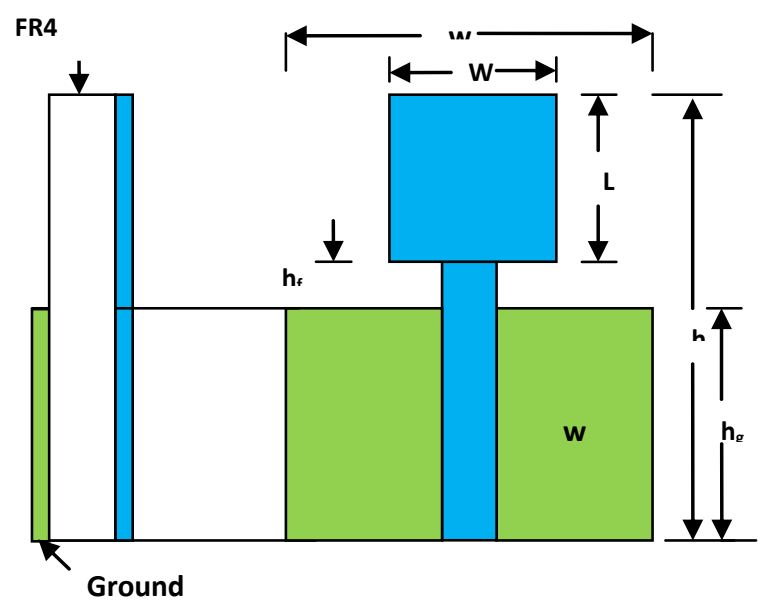

Fig 1: Geometry of the microstrip rectangular monopole antenna

For RMSA, variation in feed gap, feed line width, plate length, plate width, substrate width and dielectric constant of the substrate were investigated. In all the cases, $F_{H}$ decreases either slowly or rapidly, with the increase of the variation of the above mentioned all parameters. But for the $\left(F_{L}\right)$ and bandwidth no such trends were observed. Finally, the above parametric study of the RMSA will be of immense help in the design of printed monopole antennas.

It has been observed that the gap between the radiating patch and the ground plane below is the most crucial parameter for getting the broad bandwidth as well as proper impedance matching to maximize the antenna radiation efficiency. At the resonance frequency, the average value of the resistance is approximately $50 \Omega$ and the average value of the reactance is $0 \Omega$ indicates the adequate impedance matching occurs at the resonant frequency.

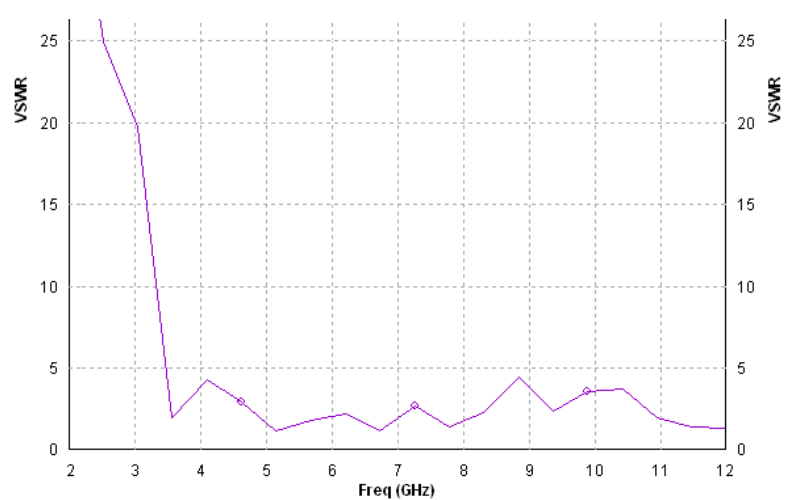

Fig 2: Plot of the simulated VSWR Vs frequency for RMSA

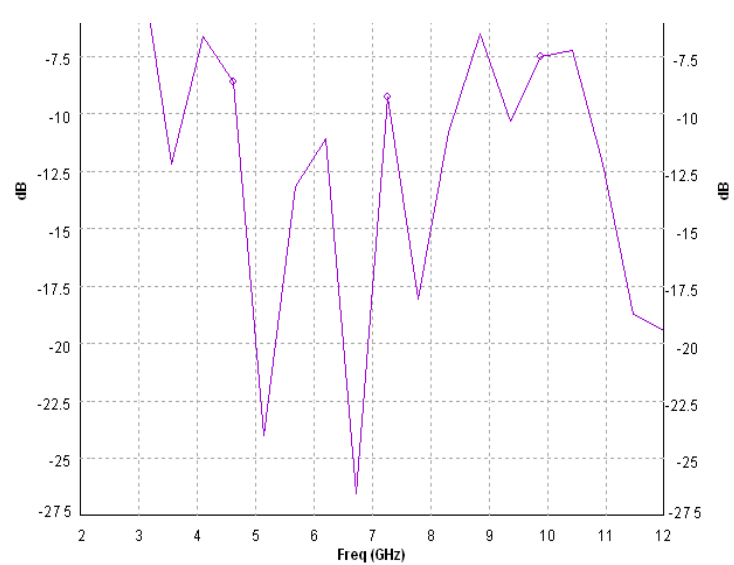

Fig 3: Plot of the Simulated Return loss vs. frequency for RMSA

\subsection{Modified Rectangular wideband microstrip Monopole Antenna}

This modified UWB monopole antenna is designed directly from the RMSA in the patch shape with some modifications as shown in figure 4 . By cutting square patch to the antenna, the proposed antenna can obtain good VSWR in the vicinity of $11 \mathrm{GHz}$. This behavior is largely because this cut introduces additional parameter, which affect the coupling between compact planer monopole antenna and the ground plane such that the proposed antenna's impedance matching can be fine tune and hence much enhanced impedance bandwidth can be achieved [9].

It is observed that the return loss curve has several resonance frequencies close to $5.1,6.8,7.8$ and $11.4 \mathrm{GHz}$. The little difference between the curves is probably due to intrinsic properties of FR4 substrate. According to [16], if a slot is etched on the active zone of the patch antenna it is possible to obtain a wider impedance bandwidth. Based on Figure 6, it is observed that the application of rectangular-shaped slot on the proposed antenna has introduced a resonant frequency at $6.8 \mathrm{GHz}$. By employing the slot structure, capacitive reactance has been introduced on the patch antenna which helps cancel out the inductive reactance of the feed component

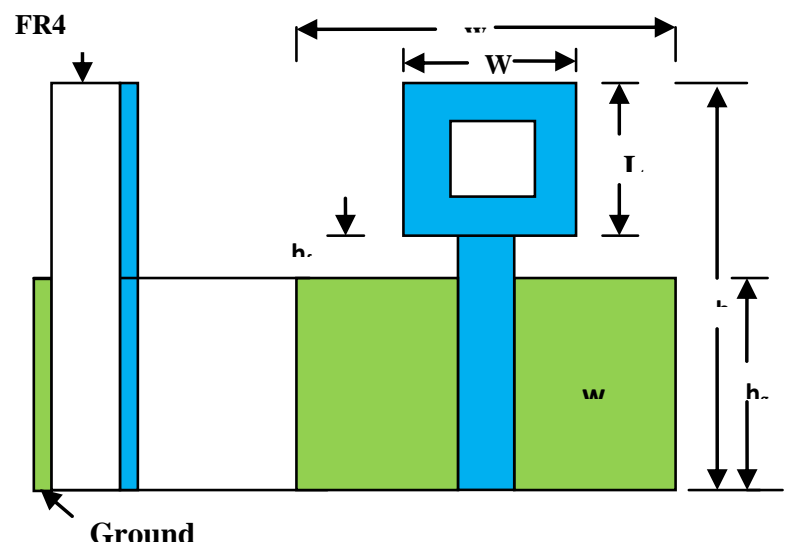

Fig 4: Geometry of the microstrip modified RMSA monopole antenna 


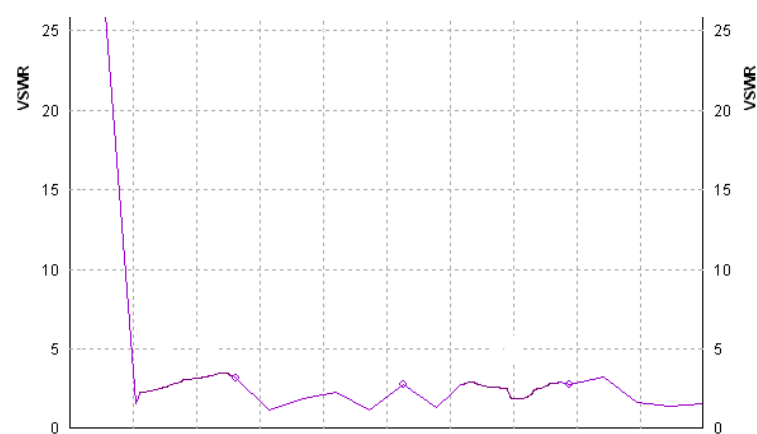

Fig 5: Plot of the simulated VSWR Vs frequency for modified RMSA monopole antenna.

Bandwidth extension can also be achieved by truncating the patch antenna diagonally at the lower edge. This technique has an effect on the antenna geometry which leads to a discontinuity in the microstrip line [17]. Owing to this approach, a second resonance frequency is introduced at 7.8 GHz. The capacitive coupling between the patch antenna and the ground plane is tuned to achieve a wider impedance bandwidth. The vertical notch is introduced on the partial ground plane to satisfy the $10 \mathrm{~dB}$. Figure 5 shows the voltage standing wave ratio (VSWR) characteristic of the antenna. This figure shows that the VSWR of the antenna remains less than 2 over a bandwidth range of 2.5 to $12 \mathrm{GHz}$. The result indicates that the VSWR complies with the UWB characteristic and the same frequency region also displays the return loss curve less than $-10 \mathrm{~dB}$, as seen in Figure 6.

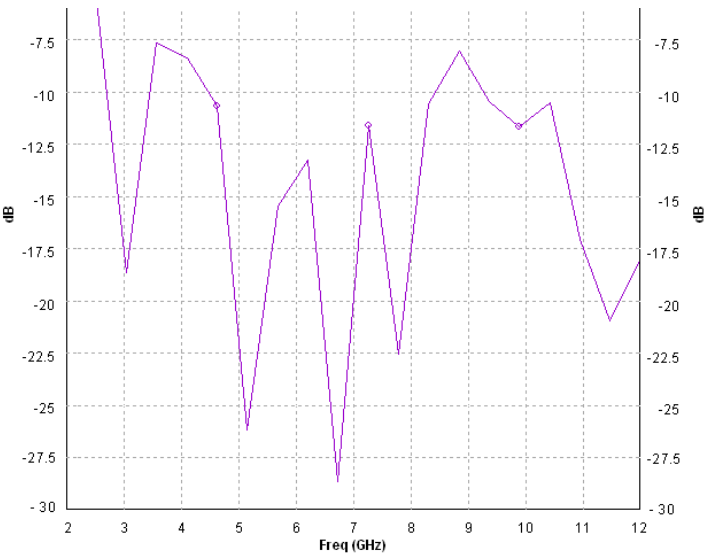

Fig 6: Plot of the Simulated Return loss vs. frequency for modified RMSA monopole antenna.

\subsection{Circular disc wideband microstrip Monopole Antenna}

First we have investigate in depth the circular disk printed monopole antenna as shown Fig.7 and modify its structure by etching out some portion of it as shown in Fig. 10 for UWB applications. The second UWB antenna has slightly less BW than the previous one but it has higher efficiency and reduced size. We have used conventional rectangular microstrip line as feed line for printed UWB antennas which are properly matched to the antenna impedance. In future we will also investigate other broadband matching techniques to further improve the UWB performance of the printed monopole antennas.

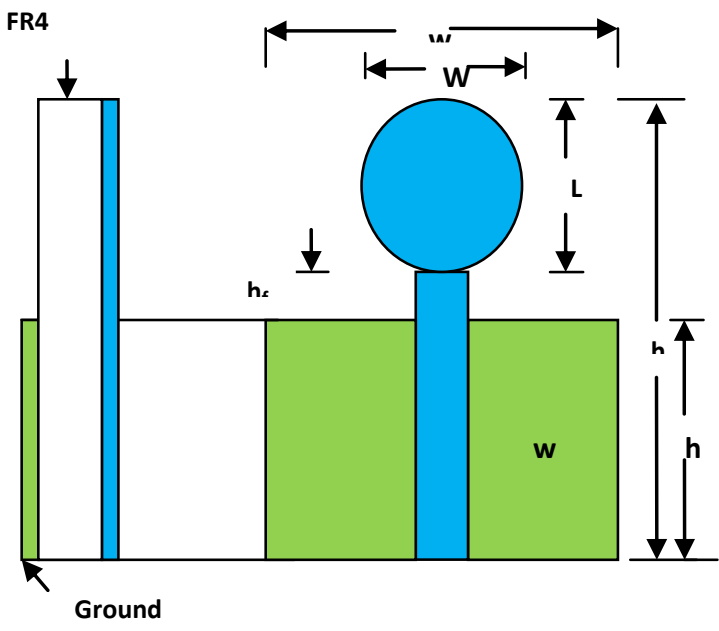

Fig 7: Geometry of the microstrip Circular disc monopole antenna

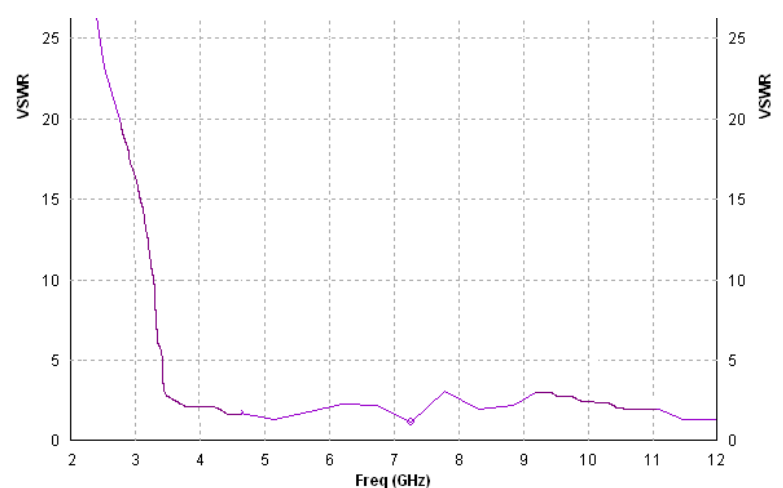

Fig 8: Plot of the simulated VSWR Vs frequency for Circular disc monopole antenna

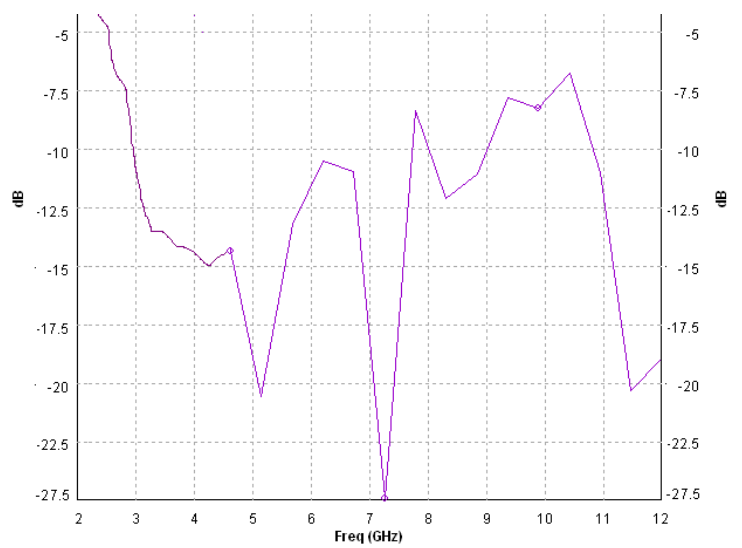

Fig 9: Plot of the Simulated Return loss vs. frequency Circular disc monopole antenna

\subsection{Modified Circular disc wideband microstrip Monopole Antenna}

This modified UWB monopole antenna is designed directly from the circular disc monopole antenna with some modifications as shown in figure 10. The proposed antenna can obtain good VSWR. We have used the same glass epoxy FR4 substrate with 4.4 relative permittivity and $1.59 \mathrm{~mm}$ 
thickness. The cut introduces additional parameter, which affect the coupling between compact planer monopole antenna and the ground plane such that the proposed antenna's impedance matching can be fine tune and hence much enhanced impedance bandwidth can be achieved, as shown in the simulated VSWR and return loss plot. It is observed that the return loss curve has several resonance frequencies close to 5.1, 7.2, 8,2 and $11.4 \mathrm{GHz}$. The little difference between the curves is probably due to intrinsic properties of FR4 substrate. According to [16], if a slot is etched on the active zone of the patch antenna it is possible to obtain a wider impedance bandwidth. Based on Figure 12, it is observed that the application of rectangular-shaped slot on the proposed antenna has introduced a resonant frequency at 7.2 GHz. By employing the slot structure, capacitive reactance has been introduced on the patch antenna which helps cancel out the inductive reactance of the feed component.

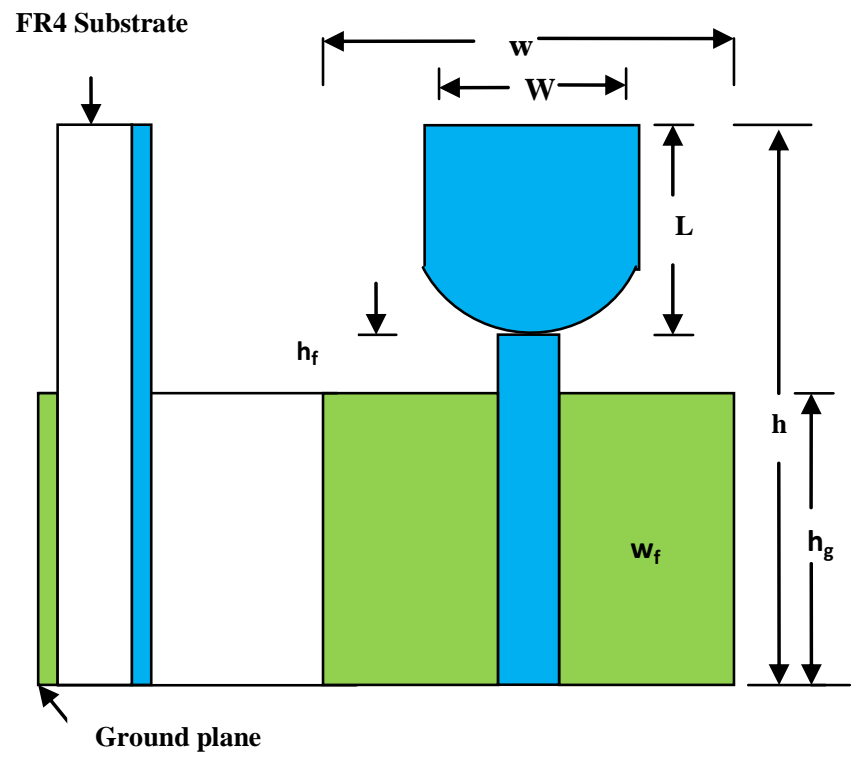

Fig 10: Geometry of the microstrip Modified circular disc monopole antenna

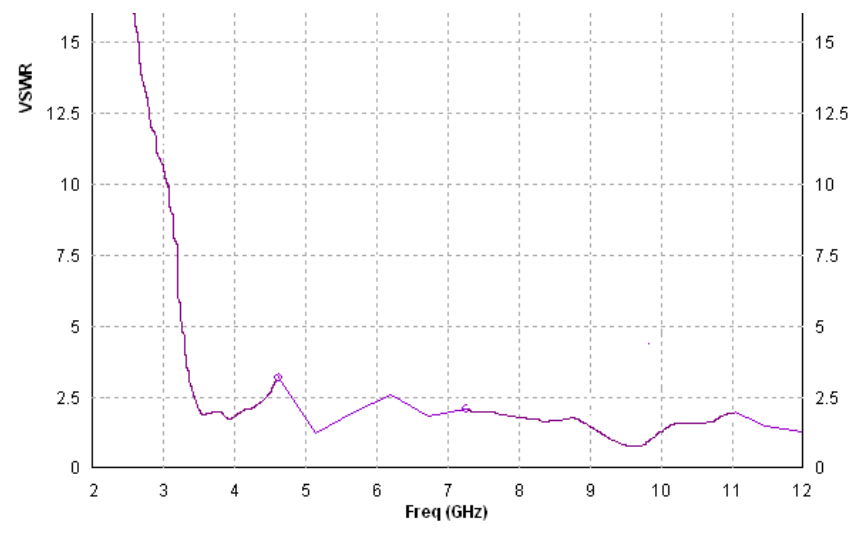

Fig 11. Plot of the simulated VSWR Vs frequency for Modified circular disc monopole antenna

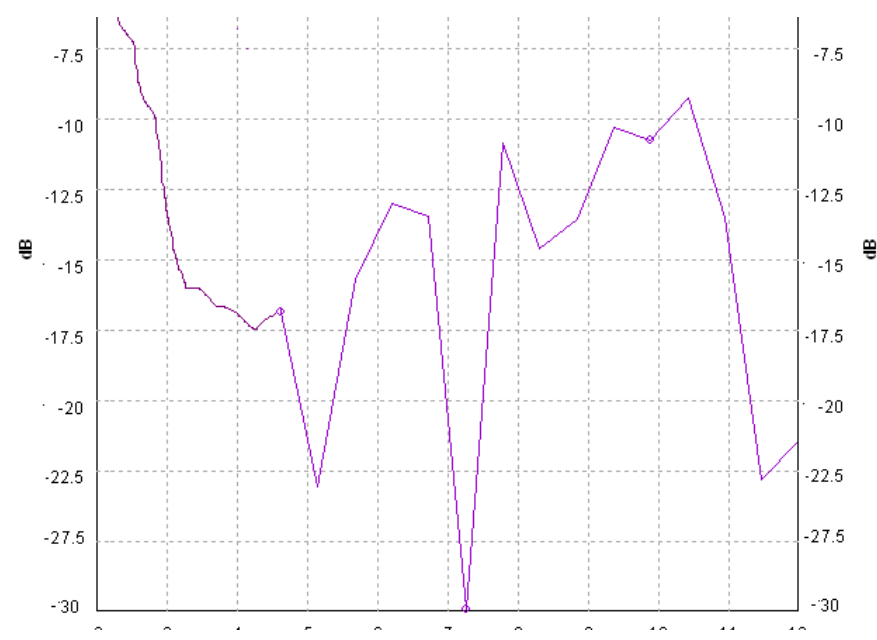

Fig 12: Plot of the Simulated Return loss vs. frequency Modified circular disc monopole antenna

\section{CONCLUSION}

In this paper, we have investigated printed wideband monopole antennas, which are basically a printed microstrip antennas with the etched ground plane. Printed wideband monopole antennas are less fragile, planar and can be integrated with the integrated circuits unlike previous monopole antennas which have non-planar or protruded structures above the ground plane. In particular, we have simulated four types of compact wideband monopole antennas namely rectangular, modified rectangular, circular and modified circular disk printed monopole antennas. The second and fourth antenna are compact and has higher efficiency whereas the first and third antenna has slightly wider BW. The E-plane radiation of all the printed monopole antennas are in the form of 8 shapes and it is slightly distorted at higher frequencies. The H-plane radiation pattern has omnidirectional patterns which also become distorted at the higher frequencies of the $\mathrm{BW}$. The novel Wideband antenna configuration is simple and compact in size providing broadband impedance matching, and consistent radiation pattern within the UWB frequency range.

\section{REFERENCES}

[1] Revision of part 15 of the commission's rules regarding Ultrawideband transmission system, first note and order Federal Communication, ET-Docket, pp. 98-153, 2002.

[2] X. H. Wu and Z. N. Chen, "Comparison of planer dipoles in UWB applications," IEEE Trans. Antennas Propag., vol. 53, pp. 1973-1983, 2005.

[3] D. C. chang, J. C. Liu, and M. Y. Liu, "A novel tulip shaped monopole antenna for UWB applications," Microwave Opt Technol. Lett., vol. 48, pp. 307-302, 2006.

[4] X. H. Wu, Z. N. Chen, and N. Yang, "Optimization of planer diamond antenna for single based and multiband UWB wireless communication," Microwave Opt Technol. Lett., vol. 42, pp. 451-455, 2004. 
[5] X. H. Wu and A. A. Kishk, "Study of an ultra wideband onmidirectional rolled monopole antenna with trapezoidal cuts," IEEE Trans. Antennas Propag., vol. 56 pp. 259-263, 2008.

[6] M. J. Ammann and Z. N. Chen, "Wideband monopole antennas for multiband wireless systems," IEEE Antennas Propag. Mag., vol. 45, no. 2, pp. 146-150, Apr. 2003.

[7] T. Yang and W. A. Davis, "Planer hal-disk antenna structures for ultrawideband communications," in proc. IEEE AP-S Int. Symp., vol. 3, pp. 2508-2511, Jun. 2004.

[8] L. Jian xin, C. C. Chiau, X. Chen, and C. G. Parini, "study of a printed circular disc monopole antenna for UWB systems," IEEE Trans. Antennas Propag., vol. 53 no. 11 pp. 3500-3504, Nov. 2005

[9] S. H. Choi, J. K. Wong, and C. L. Tang, "Ultra wideband square monopole antenna for UWB applications," Microw. Opt. Technol. Lett., vol. 40, no. 5 pp. 399-401, Mar. 2004

[10] H. Ma, Q-X. Chu and Q. Zhang, "Compact dual band printed monopole antenna for WLAN applications," Electron. Lett., vol.44, no. 14, pp. 834-835, Jul. 2008
[11] C.-Y. Pan, T.-S. Horng, W.-S. Chen and C.-H. Haung, "Dual wideband printed monopole antennas for WLAN/WiMAX applications," IEEE Antenna Wireless Proag. Lett., vol. 6, pp. 149-151, 2007.

[12] K.-L. Wong and T.-W. Kang, "GSM 850/900/1800/1900/UMTS printed monopole antenna for mobile phone applications," Microw. Opt. Technol. Lett. vol. 50, no. 12 pp. 3192-3198, Dec. 2008.

[13] Y. L. Kuo and K. -L. Wong, "Dual polarised monopole antenna for wireless LAN operation," IEEE Int. Antennas Propag., Symp. Dig., pp. 80-83, 2002.

[14] N. P. Agrawall, G. Kumar, and K. P. Ray, "Wide band planer monopole antennas," IEEE Trans. Antennas Propag., vol. 46, no. 2, Feb. 1998.

[15] M. Hammoud, P. Poey and F. Colombel, "Matching the input impedance of a broadband disc monopole," Electron. Lett., vol. 29, no. 4, pp. 406-407, Feb. 1993.

[16] I. Pele, "Antenna design with control of radiation pattern and frequency bandwidth," Antenna and Prpoag. Society International Symposium, pp. 783-786, Jun. 2004.

[17] K. C. Gupta, R. Garg, I. Bahl, P. Bhartia, “ Microstrip lines and slotlines," Artech house, Second ediation, 1996. 